\title{
Development of Sea Surface Wind Monitoring System using Marine Radar
}

\author{
Jun-Soo Park $\bigoplus^{*}$ \\ "Department of Naval Architecture and Ocean System Engineering, Kyungnam University, Changwon, Republic of Korea
}

\section{선박용 레이다를 이용한 해상풍 모니터링 시스템 개발}

\author{
박준수(10* \\ "경남대학교 조선해양시스템공학과
}

KEY WORDS: Sea surface wind 해상풍, Marine radar 선박용 레이다, Radar signal processing 레이다 신호 처리, 3D FFT 3차원 고속 푸리에 변환, Signal to noise ratio 신호대잡음비, Normalized radar cross section 정규화된 레이다 반사면적

\begin{abstract}
A wave buoy commonly used for measurements in marine environments is very useful for measurements on the sea surface wind and waves. However, it is constantly exposed to external forces such as typhoons and the risk of accidents caused by ships. Therefore, the installation and maintenance charges are large and constant. In this study, we developed a system for monitoring the sea surface wind using marine radar to provide spatial and temporal information about sea surface waves at a small cost. The essential technology required for this system is radar signal processing. This paper also describes the analytical process of using it for monitoring the sea surface wind. Consequently, developing this system will make it possible to replace wave buoys in the near future.
\end{abstract}

\section{1. 서 론}

우리나라는 한반도에 위치해 지형적 특성상 해양 기후에 많 은 영향을 받는다. 그래서 해양 기상을 관측하여 실생활 뿐 아 니라 각종 산업에 활용하기 위해 많은 비용과 노력을 투자하고 있다.

해양 기상의 대표적인 자료에는 조위, 파고, 파주기, 파방향, 유향, 유속, 풍향, 풍속 등이 있다. 이들을 관측하기 위해 기상 청, 국립해양조사원 등에서 다양한 장소에 다양한 장비를 설치 해서 지속적으로 관측하고 있으며 관측한 자료를 바탕으로 생 활 및 산업에 활용할 수 있는 예보 자료를 도출하고 있다.

해양 기상을 관측하는 대표적인 방법은 부이(해양기상부이, 파 고부이를 통칭함)이나 등표에 관측 센서를 설치하여 계측하는 것 으로 한반도의 삼면에 다수의 부이와 등표가 설치되어 운용되고 있다. 현재로서는 부이를 통해 계측한 값이 가장 신뢰성이 높다. 그런데 이런 장비들을 설치하고 유지하기 위해서 많은 비용이 지 속적으로 발생하고 있다. 특히 선박과의 충돌이나 태풍과 같은 거대한 외력에 의해 파손되거나 유실되는 위험에 항상 노출되어
있다. 그래서 이를 대체하거나 보조할 계측 장비의 필요성이 대 두되고 있다. 일반적으로 대양을 운항하는 선박은 연안에서와 같 이 부이나 등표가 획득한 객관적인 파랑 정보를 이용하기 어렵 다. 특히 지역적인 파랑 정보를 실시간으로 얻을 수 없다. 그래서 현재까지는 단순히 목측과 같은 주관적인 파랑 정보에 의존할 수 밖에 없다. 이러한 현실정을 개선하고 선박, 인명 및 화물 등의 안전을 확보하기 위하여 IMO(International Maritime Organization) 의 해양안전위원회(Maritime Safety Committee)에서는 해양 기상 예보를 활용하고 관측하는 것을 권고하고 있으며 선박의 성능을 좀 더 정확하게 평가하기 위하여 ISO(International Organization for Standardization)에서도 규정을 도입하여 해양 기상을 계측하 는 것을 또한 권고하고 있는 상황이다(IMO, 2009; ISO, 2015).

이러한 권고에 적극적으로 대응하기 위해서 본 연구에서는 저 가의 선박용 레이다를 이용한 원격 시스템으로 공간 및 시간상 해상 기상, 특히 해상풍의 계측 시스템 및 기술을 제안하려고 한 다. 앞서 언급된 바 있는 선박의 속력 시운전 데이터 해석에 의한 속력, 동력 및 프로펠러 축 속력 성능 평가의 가이드라인 ISO 15016:2015에서 해양 환경 계측에서 해상풍을 언급하고 있다

Received 15 December 2017, revised 25 January 2018, accepted 25 January 2018

Corresponding author Jun-Soo Park: +82-55-249-2655, junsoopark@kyungnam.ac.kr ORCID: https://orcid.org/0000-0001-6409-5721 It is noted that this paper is revised edition based on proceedings of KSOE 2015 in Daejeon. 
(ISO, 2015). 기 서술된 과학적인 관점에서의 해양 기상뿐만 아니 라 해양 공학에서 기상학과 해양학을 합쳐 해양기상(Metocean)이 라고 일컫는 분야에서 해상풍의 계측은 해양 자원 개발에 필요충 분 요건의 중요한 자료로 활용된다.

아울러 선행 연구를 통해 선박용 레이다를 이용한 파랑 계측 은 국산 상용제품이 이미 나와 있을 정도로 기술 수준이 향상 되었다(Park et al., 2006a; Park et al., 2006b). 그에 반해 해상풍 을 계측하는 기술은 거의 전무하며 아직 선진국 수준에 비견할 수 없는 상태이다.

\section{2. 파랑 레이다 영상}

파랑 레이다 영상이란 해수면에 반사된 레이다 후방산란 신 호를 화면에 나타낸 영상으로 해수면의 상태를 직간접적으로 나타내는 해양 정보들이 내포되어 있기 때문에 이를 추출하는 기법 연구들이 많이 진행되었다. 가장 대표적인 것이 파고, 파 주기, 파방향 등이고 이와 관련된 상용 제품도 다수 판매되고 있다(Young et al., 1985; Ziemer et al., 1987; Nieto et al., 1999; Hirayama et al., 2001; Park, 2005). 현재는 분석 기법을 고도화 하여 해상풍의 방향 및 속력 성분을 추출하는 연구가 많이 진 행되었다(Dankert et al., 2005; Dankert and Horstmann, 2007). 본 연구에서는 해상풍 모니터링 시스템을 개발하기 위해 진행된 계측 및 해석 기법 그리고 현장 실험에 대한 결과를 기술하려 고 한다.

\section{3. 해상풍 추정}

해상풍은 해수면(Free surface or sea surface)과 관련된 대기의 움직으로 정의되며 일반적으로 해상풍은 해수면에 매우 가깝게 측정한다. 통상 해수면에서 해발 $10 \mathrm{~m}$ 높이에서 계측하는 것이 보편적이다. 본 연구에서는 일반적으로 한 지점에서 계측하는 방법과는 달리 레이다를 이용하여 해상의 파도로부터 해상풍을 추정하는 것이다. 따라서 해상풍 추정은 파랑 레이다 영상으로 부터 파랑과 해상풍의 관계를 이용한다. 특히 파랑 레이다 영상 으로부터 풍파(Wind wave)와 너울(Swell)을 구분할 수 있다(Park et al., 2006a). 이 중 풍파의 후방산란 신호의 수신 방향과 분포 및 강도를 활용하여 추정한다.

\section{1 풍향}

해수면 위로 바람이 불게 되면 Fig. 1과 같이 바람이 불어오 는 방향으로 경사가 완만해지는 파면이 생기게 된다. 이로 인해 바람이 불어오는 방향으로는 레이다 반사 신호가 강해지고 그

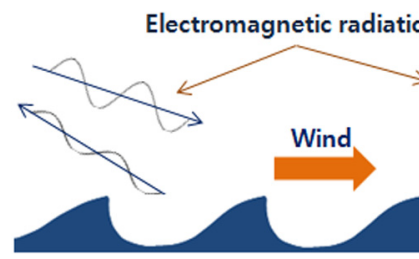

(a) Outgoing wind direction

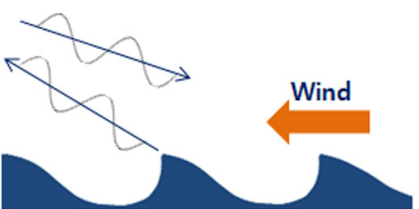

(b) Incoming wind direction
Fig. 1 Difference of radar signal reflection by wind direction

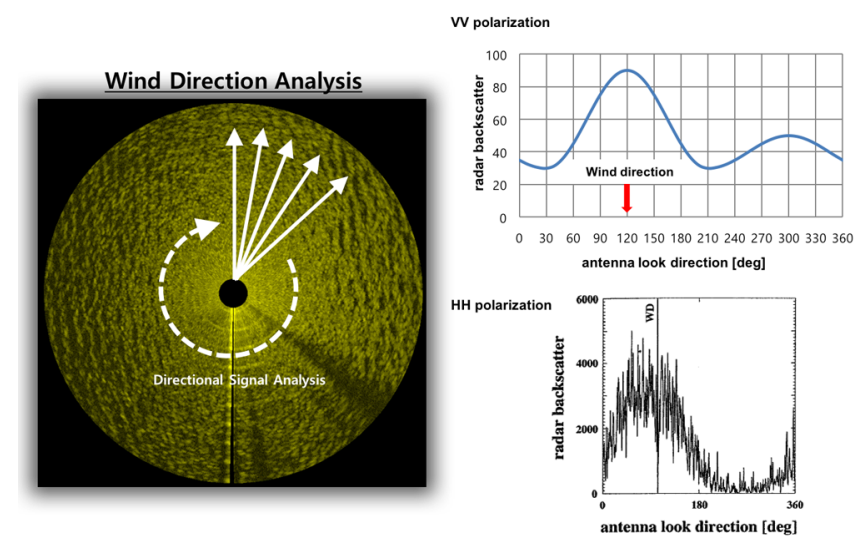

Fig. 2 Scheme of wind direction analysis and examples of azimuthal dependency of radar backscatter

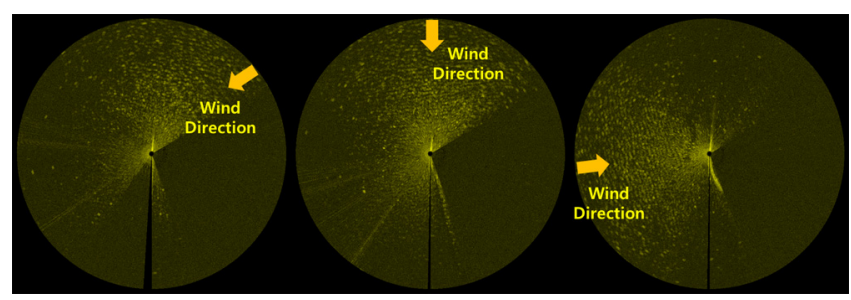

Fig. 3 Examples of PPI image including azimuthal dependency of radar backscatter by wind direction

반대 방향은 약해지는 현상이 발생한다(Hatten et al., 1998). 따 라서 Fig. 2와 같이 레이다 후방산란 신호를 수신하는 방향별로 신호의 강도를 계측하고 그 강도가 가장 큰 방향을 풍향으로 정의하는 것이 이 기법의 주요 내용이다(Hatten et al., 1998). 다 만 레이다 신호 안에 해수면 반사 신호 외의 잡음 성분이 포함 될 경우가 많기 때문에 식 (1)과 같은 근사식으로 풍향을 추정 한다(Moore and Fung, 1979).

$$
\eta(\theta)=A+B \cos (\theta-\phi)+C \cos 2(\theta-\phi)
$$

여기서 $\eta$ 는 후방산란 신호 강도, $\theta$ 는 후방산란 신호 수신 방향, $\phi$ 는 해상풍 방향, $A, B, C$ 는 계측 후방산란 신호와 식 (1)의 $\eta$ 와 의 오차가 최소가 되기 위한 계수들이다.

Fig. 3에 해상풍 방향에 따라 레이다 신호의 밝기가 달라지는 PPI(Plan position indicator) 영상의 예를 나타내었다.

\section{2 풍속}

레이다 신호를 이용하여 풍속을 계측하는 기법은 2 가지가 있 다. 첫 번째는 풍속과 파고와의 관계로부터 풍속을 추정하는 기 법으로 레이다를 이용한 파고 추정 기법에서 착안한 것이다 (Park et al., 2006a; Park et al., 2006b).

해상 또는 육상 의 풍속 상태를 12 등급으로 나눈 보퍼트 스케 일(Beaufort scale)에서 알 수 있듯이 등급이 증가할수록 풍속과 더불어 파고도 높아진다. 파고를 추정하는 기법에서 도입한 신 호대잡음비(Signal to noise ratio, SNR)를 풍속 산정에 도입하여 이 값과 풍속과의 관계를 식 (2)과 같이 산정하게 된다면 $S N R$ 값 을 구해서 파고를 추정하듯이 풍속도 추정이 가능하다. 이러한 

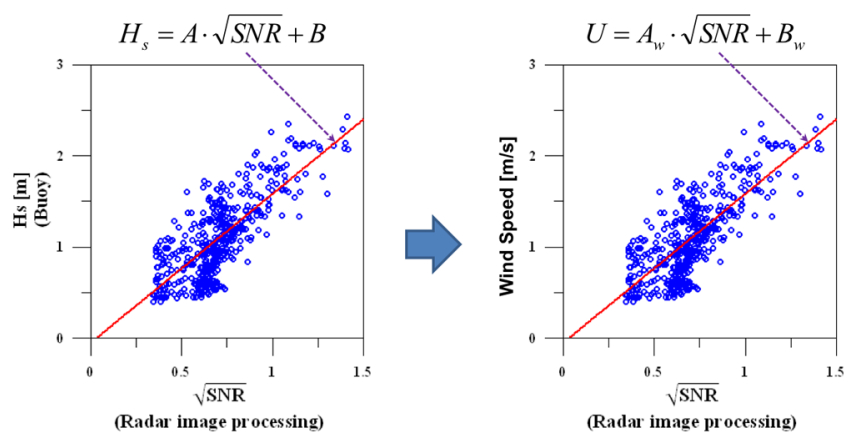

Fig. 4 Concept scheme of wind speed estimation similar to wave height estimation using $\sqrt{S N R}$

관계를 Fig. 4에 나타내었다.

$$
U=A \sqrt{S N R}+B
$$

여기서 $U$ 는 풍속이고 $S N R$ 은 식 (3)과 같이 정의한다. 그리고 $A$, $B$ 는 계측을 통해 구할 수 있는 상수이다.

$$
S N R=\frac{\Sigma(\text { Wave Energy })}{\Sigma(\text { Background Noise })}
$$

풍속을 추정하는 두 번째 기법은 정규화된 레이다 반사면적 (Normalized radar cross section, NRCS)을 이용하여 추정하는 기 법이다. 풍속에 따라 해수면이 거칠어지는 정도가 달라져 그에 따른 레이다 신호 반사율도 달라지므로 첫 번째 기법과 같은 방식으로 $\mathrm{NRCS}$ 와 풍속과의 관계를 식 (4)과 같은 형태로 추정 한다. Fig. 5 에 개념적 기법을 소개하였다.

$$
\begin{aligned}
\text { From radar eq. } \frac{P_{r}}{P_{t}} \propto \frac{\sigma}{R^{4}} \\
P_{t}: \text { Transmitted power } \\
P_{r}: \text { Received power } \\
\sigma: \text { Radar cross section (RCS) } \\
R: \text { Range [m] }
\end{aligned}
$$

Substitute $\sigma=\sigma_{0} \cdot \Delta A$ at radar eq., consequently $\sigma_{0} \propto \frac{P_{r}}{P_{t}} R^{3}$

From measured radar signal, calculate $\sigma_{0}$ (NRCS; Normalized Radar Cross Section) and it measures the actual velocity at that time to complete the estimation formula, as shown below
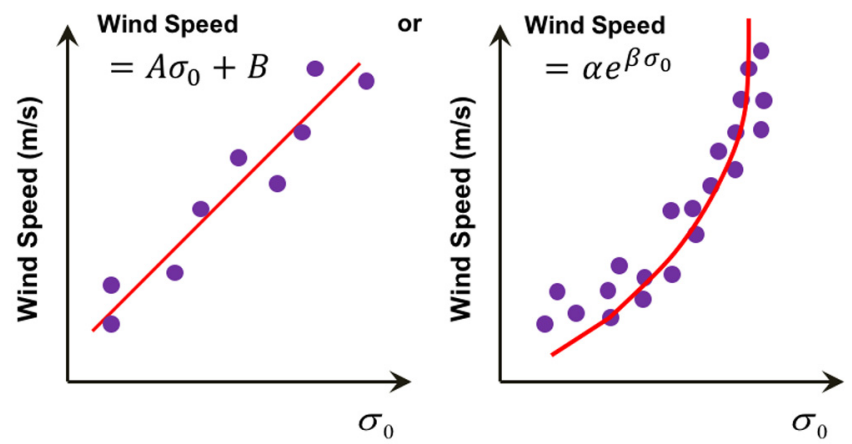

Fig. 5 Concept scheme of wind speed estimation similar to wave height estimation using NRCS

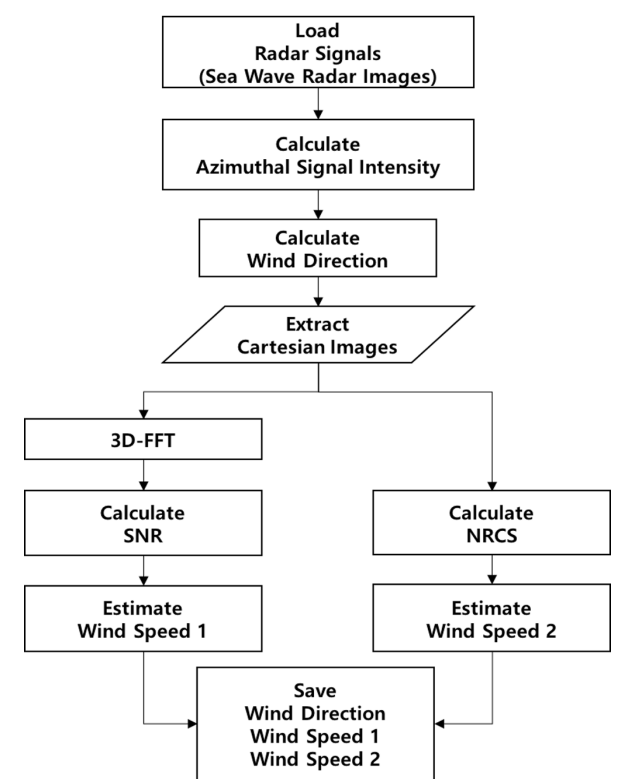

Fig. 6 Flowchart of estimation for sea surface wind of direction and speed

$$
U=A \sigma_{0}+B \text { or } U=\alpha e^{\beta \sigma_{0}}
$$

여기서 $A, B, \alpha, \beta$ 는 계측을 통해 구할 수 있는 상수이고 $\sigma_{0}$ 는 $\mathrm{NRCS}$ 이다.

이상과 같이 해상풍 추정과 관련한 파랑 레이다 영상으로부터 해상풍 풍향 및 풍속 추정의 과정을 Fig. 6 에 흐름도로 표현하였다.

\section{4. 결 과}

현장 시험을 통하여 획득한 레이다 데이터는 2015년 4월초부 터 9월초까지 계측한 것으로 울산 주전의 이덕서 등표 주변에 서 계측되었다. 레이다로 계측할 수 있는 범위 내에 풍향, 풍속 을 계측하는 등표가 있기 때문에 앞서 설명한 해상풍 추정 기

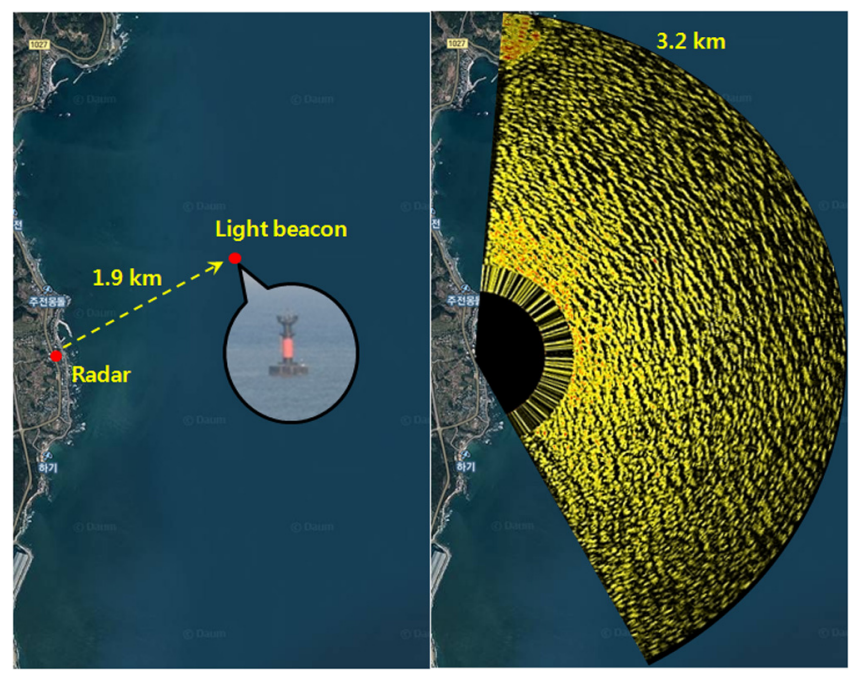

Fig. 7 Location of radar installation, light beacon and radar scanning range 
Table 1 Specifications of marine radar

\begin{tabular}{ccc}
\hline \hline & Length & $2.65 \mathrm{~m}$ \\
Antenna & Beamwidth (H) & $0.9^{\circ}$ \\
radiators & Beamwidth (V) & $22^{\circ}$ \\
& Rotation & $42 \mathrm{rpm}$ \\
\hline \multirow{2}{*}{ RF } & Frequency & $9375 \mathrm{MHz} \pm 50 \mathrm{MHz}$ \\
transceiver & Output power & $25 \mathrm{~kW}$ \\
& Pulselength \& PRF & $0.06 \mu \mathrm{s}, 3000 \mathrm{~Hz}$ \\
& Noise figure & $60 \mathrm{MHz}, \mathrm{Logarithmic}$ \\
& & $\leq 5 \mathrm{~dB}$ \\
\hline
\end{tabular}

법을 이용하여 레이다 신호를 분석한 결과와 등표에서 계측한 값을 비교할 수 있었다. Fig. 7에 레이다 설치 및 등표의 위치를 나타내었고 설치된 레이다 스캐닝 영역을 나타내며 해수면의 후방산란 신호 영상을 나타내었다.

Fig. 7 에서 확인할 수 있듯이 해수면의 정보는 약 $180^{\circ}$ 이내에 서 얻을 수 있기에 풍향이 $0 \sim 180^{\circ}$ 인 경우에 대해서만 레이다 신 호를 분석하여 비교하였다. 현장 시험에 사용된 레이다의 사양 은 Table 1 과 같다.

\section{1 풍향}

등표에서 계측한 풍향과 레이다 신호를 분석해서 추정한 결 과의 산포도(Scatter diagram)를 Fig. 8에 나타내었다. 상관계수 (Correlation coefficient)가 0.6678로 낮은 수준이다. 이러한 연유 는 4. 결과에서 언급한 내용과 Fig. 7 에서 레이다 스캐닝 영역에 서 확인할 수 있는 바와 같이 해수면의 정보가 공간상 $180^{\circ}$ 가 되지 않는다. Fig. 2 와 같이 $360^{\circ}$ 의 해수면 정보를 가지고 해석 하지 못한 결과라고 유추된다. 향후 $360^{\circ}$ 의 해수면 정보를 얻을 수 있는 현장을 확보하는 것이 해석 정확도를 높이기 위한 기 본요건일 것으로 인식된다.

하지만 Fig. 9와 같이 계측 값과 추정 값을 비교해보면 유사 한 경향을 보인다. 큰 오차를 보이는 특정 구간에서도 경향을 유지하는 것으로 보아 분석 기법을 보완하면 정도가 높은 결과 를 얻을 수 있을 것으로 판단된다.

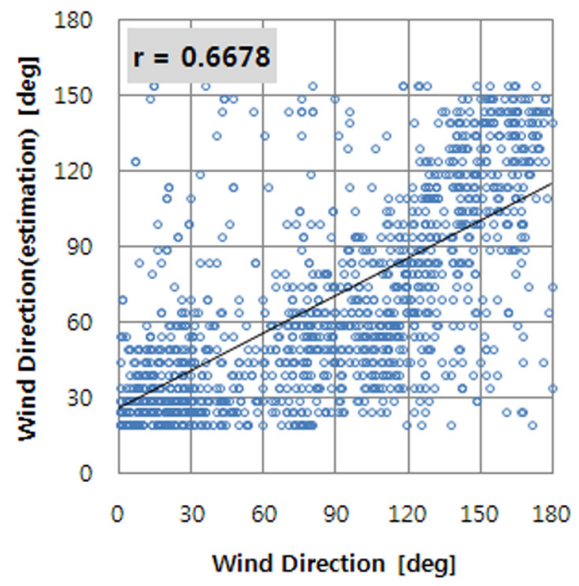

Fig. 8 Scatter diagram of wind direction (In situ measurement vs. radar estimation)

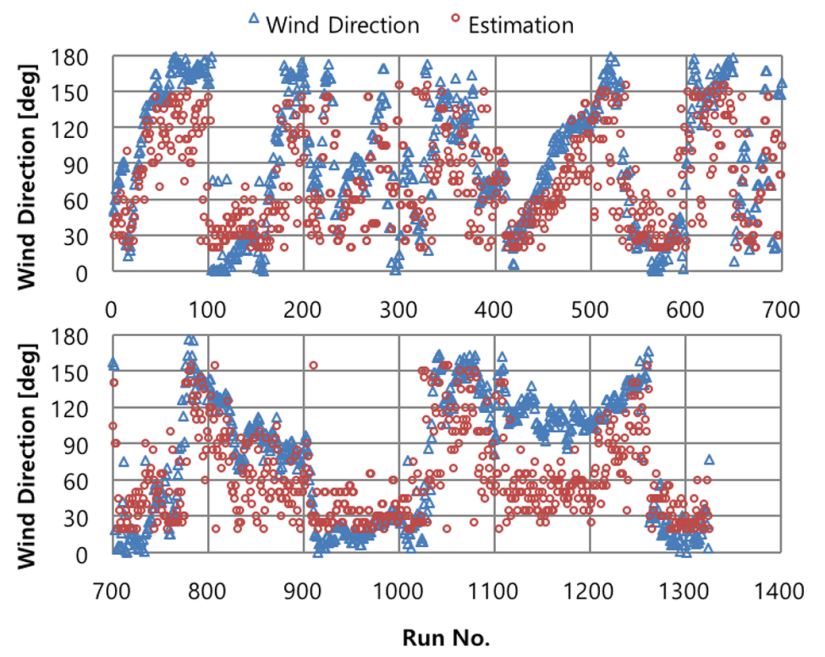

Fig. 9 Comparison of the wind direction (In situ measurement vs. radar estimation)

\section{2 풍속}

$\sqrt{S N R}$ 과 풍속의 산포도 및 풍속 추정 식을 Fig. 10에 나타내 었다. 그리고 이 추정 식을 레이다 신호 분석에 적용한 결과의 산포도를 Fig. 11에 나타내었다. 계측 값과 추정 값의 상관계수

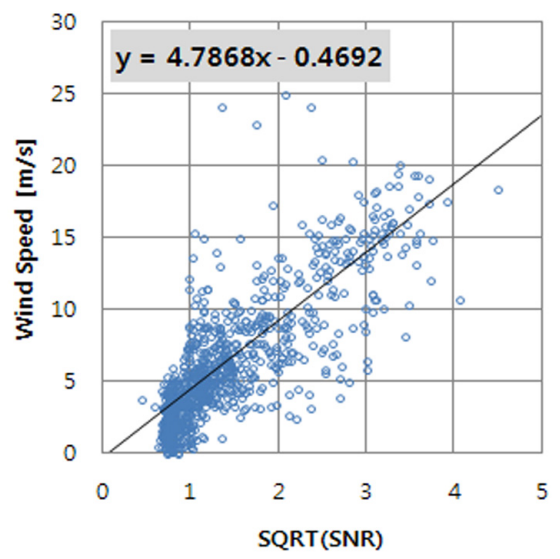

Fig. 10 Scatter diagram of $\sqrt{S N R}$ versus measured wind speed in situ

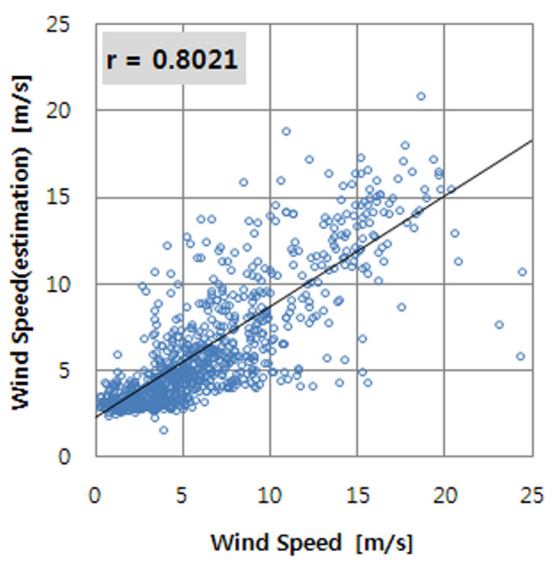

Fig. 11 Scatter diagram of wind speed (In situ measurement vs. estimation using $\sqrt{S N R}$ ) 

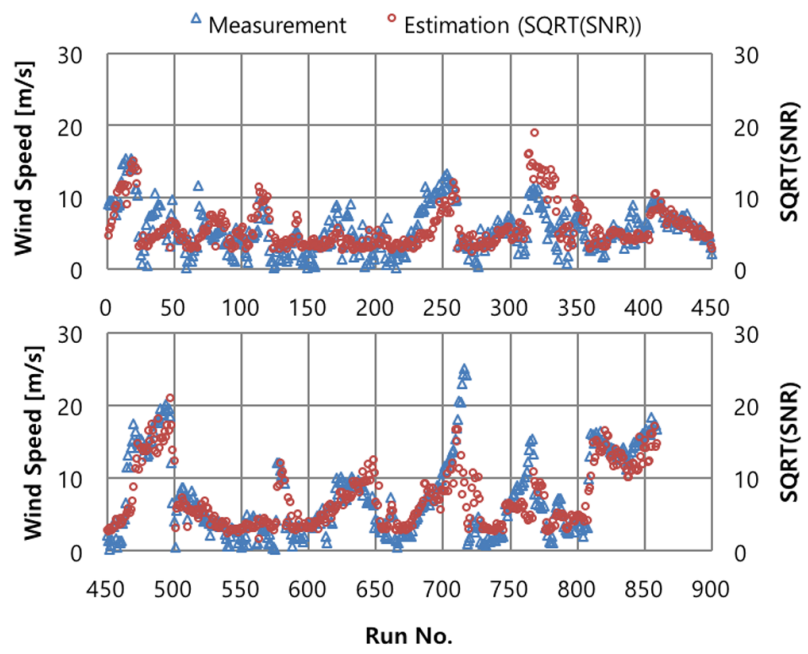

Fig. 12 Comparison of wind speed (In situ measurement vs. estimation using $\sqrt{S N R}$ )

가 0.8021 의 높은 수준이며 Fig. 12을 통해서 두 데이터의 유사 성을 한 번 더 확인할 수 있다.

NRCS와 풍속의 관계는 선형보다는 지수형태로 추정 식을 구 할 경우 상관계수가 조금 더 높았다. Fig. 13에 NRCS와 풍속의 산포도 및 추정 식을 나타내었다. Fig. 14에는 계측 값과 추정

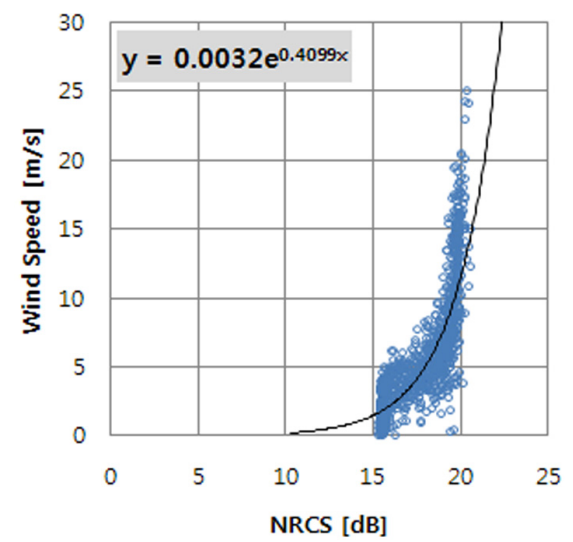

Fig. 13 Scatter diagram of NRCS versus measured wind speed in situ

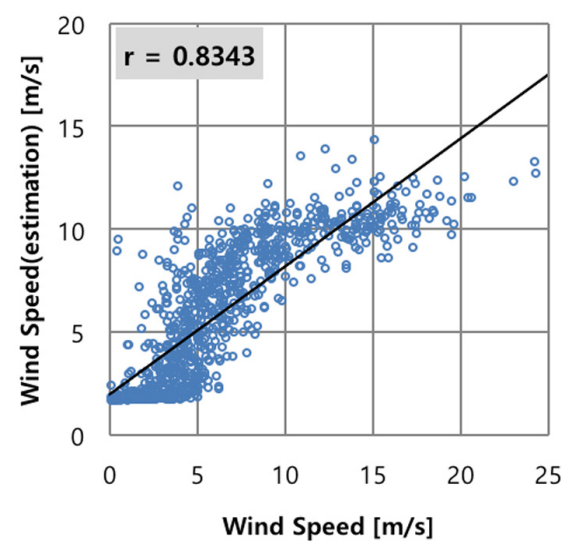

Fig. 14 Scatter diagram of wind speed (In situ measurement vs. estimation using NRCS)
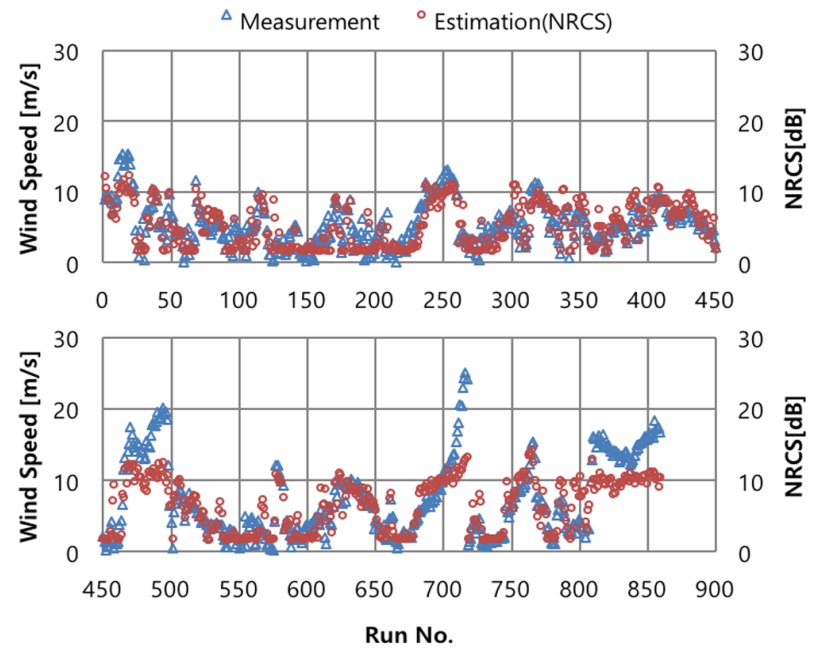

Fig. 15 Comparison of wind speed (In situ measurement vs. estimation using NRCS)

값의 산포도 및 상관계수를 나타내었다. 상관계수는 0.8343 으로 $\sqrt{S N R}$ 을 이용한 기법보다 약간 높은 수치이다. Fig. 15에 계측 값과 추정 값을 비교한 결과를 나타내었다.

Fig. 12 와 Fig. 15 를 비교해보면 두 기법의 단점이 그대로 나 타나 있다. $\sqrt{S N R}$ 은 레이다 신호에 3 차원 $\mathrm{FFT}$ 를 적용한 결과 에서 파랑의 분산성 관계(Dispersion relation)를 만족하는 성분을 파랑 에너지 성분으로 정의하는데, 실제로는 해수면 반사 신호 가 없는 경우라도 잡음성분이 전 주파수 영역에 존재하기 때문 에 파랑의 분산성 관계를 만족하는 잡음성분이 반드시 존재하 고 이로 인해 $\sqrt{S N R}$ 은 항상 일정 값 이상이 된다. 따라서 풍속 이 낮은 경우에 $\sqrt{S N R}$ 은 0 에 수렴하지 않고 일정 값 이상이 되기 때문에 Fig. 12와 같이 계측 값과의 오차가 크게 발생한다. 반면 NRCS의 경우는, 풍속이 높아질수록 NRCS값도 증가하지 만 한계 값이 존재한다. Fig. 10에서 알 수 있듯이 풍속이 $12 \sim 15 \mathrm{~m} / \mathrm{s}$ 이상이 되면 NRCS값이 $20 \mathrm{~dB}$ 내외의 값으로 수렴하게 된다. 따라서 Fig. 15 와 같이 풍속이 $15 \mathrm{~m} / \mathrm{s}$ 이상인 경우에 계측 값과의 오차가 크게 발생한다.

\section{5. 결 론}

본 연구에서는 선박용 레이다로 해상풍을 계측하는 기법을 제안하였고, 현장 시험에 의한 해석 결과를 토대로 선박용 레이 다를 이용한 해상풍 모니터링 시스템을 개발하였으며 다음과 같은 결론을 얻을 수 있었다.

(1) 풍향을 추정하는 기법은 풍향에 따라 해수면의 기울기가 달라지고, 그에 따른 레이다 후방산란 신호 강도가 달라지는 것 으로 풍향을 추정하는 아주 간단한 방법으로 접근하였지만 풍 향풍속계로 계측한 값과 의미 있는 유사한 결과를 얻을 수 있 었다. 분석 결과의 정도를 더 높이고 $360^{\circ}$ 모든 방향에 대해 레 이다 신호를 받을 수 있는 해양 환경에서도 제 성능을 발휘할 수 있도록 추가적인 연구를 통하여 성능을 향상 시킬 필요가 있다.

(2) 풍속을 추정하는 두 기법들은 큰 오차가 발생하는 풍속 구간이 존재하지만 계측 값과 매우 유사한 결과를 얻을 수 있 
었다.

(3) 정도 높은 풍속을 추정하기 위하여 본 연구에서 기술한 두 기법을 함께 적용할 수 있는 적합한 최적화 알고리즘에 대 한 추가 연구를 진행 중에 있으며 지속적인 연구로 완성된 높 은 결과를 도출할 계획이다.

(4) 현재 본 연구의 정도 향상과 해석 기법의 범용성 확보를 위해 울릉도에서 현장실험을 진행하고 있으며 지속적인 계측을 통하여 다양한 해상풍(해상 상태)에 대한 연구를 할 계획이다.

\section{후기}

이 연구는 기상청 기상산업지원 및 활용기술 개발사업 (KMIPA 2014-22010)의 지원으로 수행되었습니다.

\section{References}

Dankert, H., Horstmann, J., Rosenthal, W., 2005. Wind- and WaveField Measurements Using Marine X-Band Radar-Images Sequences. IEEE Journal of Oceanic Engineering, 30(3), 534-542.

Dankert, H., Horstmann, J., 2007. A Marine Radar Wind Sensor. Journal of Atmospheric and Oceanic Technology, 24(9), 1629-1642.

Hatten, H., Seemann, J., Horstmann, J., Ziemer, F., 1998. Azimuthal Dependence of the Radar Cross Section and the Spectral Background Noise of a Nautical Radar at Grazing Incidence. Proceedings of Geoscience and Remote Sensing Symposium, 5, 2490-2492.

Hirayama, T., Park, S.G., Hirakawa, Y., Takayama, T., 2001. Development of a Wave Field Detector using the Marine Wave Radar and Measured Example. Journal of Society of Naval Architecture of Japan, 2002(191), 51-56.

International Maritime Organization (IMO), 2009. Report of the Maritime Safety Committee on Its Eighty-fifth Session. [Online] Available at: <https://www.mpa.gov.sg/web/wcm/
connect/www/dffdba06-e82b-4cd5-a434-a3704834a272/MSC _85-26-Add.1.pdf?MOD=AJPERES $>$ [Accessed January 2018].

International Organization for Standardization (ISO), 2015. Ships and Marine Technology - Guidelines for the Assessment of Speed and Power Performance by Analysis of Speed Trial Data. [Online] Available at: <https://www.iso.org/standard/ 61902.html> [Accessed January 2018].

Moore, R.K., Fung, A.K., 1979. Radar Determination of Winds at Sea. Proceedings of the IEEE, 67(11), 1504-1521.

Nieto, J.C., Reichert, K., Dittmer, J., 1999. Use of Nautical Radar as a Wave Monitoring Instrument. Coastal Engineering, 37(3), 331-342.

Park, G.I., Choi, J.W., Kang, Y.T., Ha, M.K., Jang, H.S., Park, J.S., Park, S.G., Kwon, S.H., 2006a. The Application of Marine X-band Radar to Measure Wave Condition during Sea Trial. Special Issue of the Society of Naval Architects of Korea, 10(4), 34-48.

Park, J.S., Park, S.G., Kwon, S.H., Park, G.I., Choi, J.W., Kang, Y.T., Ha, M.K., 2006b. Development of a Wave Monitoring System Using a Marine Radar. Journal of Ocean Engineering and Technology, 20(1), 37-42.

Park, J.S., 2005. Development of Sea Surface Wave and Current Monitoring System by Using X-band Nautical Radar. PhD Dissertation, Naval Architecture and Ocean Engineering in Pusan National University.

Young, I.R., Rosenthal, W., Ziemer, F., 1985. A Three Dimensional Analysis of Marine Radar Images for Determination of Ocean Wave Directionality and Surface Currents. Journal of Geophysical Research, 90(C1), 1049-1059.

Ziemer, F., Rosenthal, W., 1987. On the Transfer Function of a Shipborne Radar for Imaging Ocean Waves. Proceedings of IGARSS '87 : Remote Sensing : Understanding the Earth as a System, The University of Michigan, Ann Arbor, Michigan, 1559-1564. 